\title{
A Practical Integrated Fault Location Method for Electrical Power Distribution Networks
}

\author{
Alireza Bahmanyar \\ Department of Electrical Engineering \\ Iran University of Science and Technology \\ Tehran, Iran \\ bahmanyar@iust.ac.ir
}

\author{
Abouzar Estebsari \\ Department of Energy \\ Politecnico di Torino \\ Turin, Italy \\ abouzar.estebsari@polito.it
}

\begin{abstract}
Future Distribution systems are supposed to be self-healing systems which can manage the faults and quickly restore the customers from outage. As the basic function of fault management systems, fault location methods play an important role in reducing the outage time and related costs. This paper aims to present a practical method that provides accurate and reliable estimations of the fault location. The proposed method is an integration of a voltage sag-based method and an impedancebased method. Following to any fault, the method first uses the voltage sag magnitudes measured by a limited number of meters to find the nearest node to the fault. Then, it checks all the lines connected to the node and uses an impedance-based method to find the exact fault location. The proposed method is applicable to large-scale distribution systems with several laterals and load taps. Simulation tests are performed on a real-life distribution system to test the method performance. The simulation study includes a comparative analysis with two other recent methods reported in the literature. The results show the better performance of the proposed method even under measurement and load data errors.
\end{abstract}

Keywords - Distribution networks; fault location; outage management; wide area-measurement.

\section{INTRODUCTION}

Distribution systems are usually made of branched networks dispersed over wide areas. Therefore, they are considerably vulnerable to faults arising from a variety of reasons such as adverse weather conditions. Over $80 \%$ of customer outages are due to distribution network faults. To reduce the social and economic impacts of outages, faults should be identified, isolated and the affected customers should be restored quickly. The overall process is usually known as outage management in which fault location is a basic function. Fault location function narrows down the patrolling and search area and hence minimizes the restoration time. It assists utility personnel to find the faulted components and quickly restore the interrupted customers connected to non-faulted sections, thanks to sectionalizing switches.

An advanced fault management system requires an accurate and reliable fault location method to realize fast service restoration. Several distribution network fault location techniques are proposed over the last two decades. The methods can be classified into impedance-based methods, methods based on sparse measurements, traveling wave-based methods, artificial intelligence-based methods, and integrated methods [1].

Impedance-based methods use the three-phase voltage and current measured at the main substation to calculate the fault location. They solve a fault location equation for all line sections, one at a time, to identify all possible solutions [2-4]. Impedance-based methods, because of their relatively low measurement requirements, are generally considered as a practical solution for conventional distribution systems. However, these methods usually lead to multiple fault location candidates for a single fault. Travelling wave-based methods mostly rely on some characteristic frequencies which appear in the fault induced travelling waves. For networks with a limited number of branches, these methods may provide accurate results [5,6]. However, for large branched distribution networks, they require measuring devices with very highfrequency sampling rates. Artificial intelligent systems are employed by some of the proposed techniques, such as neural network-based methods, as precise and fast alternatives [7,8]. Nevertheless, such methods need a large amount of actual or simulated fault cases for training process, which should be repeated by any change in the topology of the distribution network.

Inspired by the developments of distribution systems metering and communication infrastructures in recent years, a new type of fault location techniques is proposed which relies on sparse measurements [9-12]. The most known methods of this class are voltage sag-based fault location methods, which have a simple procedure. These methods consider the fault at all network nodes, one by one, and perform a load flow for each node. Then, by calculating the mismatch between the calculated voltage sags and measured voltage sags, they identify the node with the least difference as the nearest node to the actual fault location. These methods, however, mostly cannot find the exact location of the fault and in some cases, they are not able to identify the nearest node.

This paper presents the idea of a new integrated fault location method. Whenever a fault is detected, the proposed method first investigates the magnitude of fault-induced voltage sags, recorded in a limited number of network nodes, to identify the nearest node to the fault location. It then solves an impedance-based fault location equation for all lines connected to the selected node to make an estimation of the exact fault 
location. The method is tested using a simulated model of a practical 134-node feeder. Overall, the simulation study verifies the accuracy and dependability of the method for different fault resistance, fault locations, and fault types, even under measurement and load data errors, showing its potential for practical applications.

\section{THE METHOD}

The proposed method requires the pre- and during fault three-phase voltage and current measured at the main HV/MV substation. It also needs the magnitude of voltage sags recorded at a limited number of nodes, equipped with voltage meters. The measurements does not need to be synchronized, but the measured quantities should be for the same fault scenario.

The method is an integration of a voltage sag-based method and an impedance-based method. The voltage sag-based methods are based on the fact that fault induced voltage sags have different magnitudes at different network nodes $[9,10,12]$. Therefore, by measuring the magnitude of voltage sags at some nodes, it would be possible to find the fault. The voltage sagbased method of [9] assumes all network nodes to be faulted, one at a time, and performs a load flow for each node to calculate voltage sags. It then identifies the faulted node as the node with the least difference between the calculated voltage sags and measured voltage sags. The following index is a quantified representation of the idea. The $j^{\text {th }}$ node with the largest index value is the one with the least mismatch between the calculated voltage sags $\left(\Delta V_{i, j}^{c}\right)$ and measured voltage sags $\left(\Delta V_{i}^{m}\right)$, and would be the nearest node to the actual fault location.

$$
\operatorname{Index}_{j}=\frac{1}{\sum_{i=1}^{m}\left|\Delta V_{i}^{m}-\Delta V_{i, j}^{c}\right|+\varepsilon}
$$

where $m$ is the number of voltage meters and $\varepsilon$ is a small value to avoid zero denominator.

This fault location technique has two shortcomings: first, it cannot find the exact location of the fault and just identifies the nearest node to the fault; second, it cannot differentiate between neighboring nodes in some cases, especially when there are a limited number of measurements.

In the proposed solution, an impedance-based method is integrated with the above voltage sag-based method to remedy these shortcomings. As shown in the flowchart of Fig. 1, the method proposed first calculates the Index value for all network nodes to find the one with the highest value as the nearest one to the actual fault location. In the next step, the impedancebased method is employed to find the exact location of the fault within the lines connected to the selected node. If the proposed method finds the fault within the lines connected to the selected node, it reports the result, otherwise, it selects the node with the second highest value of Index and repeats the process. Studies have shown that the nearest node to the fault is always one of the nodes with the highest values of Index [9].

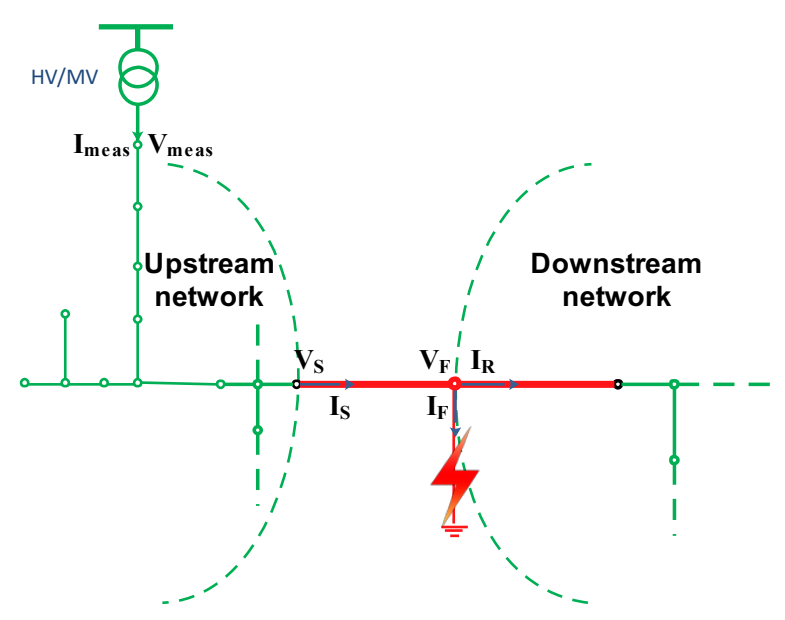

Fig. 1. Short circuit fault in a distribution network

The details of load flow algorithm is described in $[9,10,13]$. The method employed for fault location within the lines connected to each selected node is presented in the following subsection.

\section{A. Fault location within the lines}

During the process of fault location, as shown in Fig. 2, once the nearest node to the actual fault location is identified, a fault location equation should be solved for all the lines connected to the node. The employed algorithm to fulfill this task is based on the impedance-based fault location method proposed in [4]. For each line, to solve the equation, the during-fault current and voltage phasors at the sending end of the line $\left(V_{S}\right.$ and $\left.I_{S}\right)$ are required. The following algorithm is employed to calculate these values [4]:

1) Consider the network as down-and upstream networks connected by the selected line, as shown in Fig. 1;

2) Make an initial guess for the selected line current $I_{S}$ and nodal voltages (e.g. their pre-fault values);

3) Calculate the load current of each node in the upstream network (based on the load model);

4) Calculate the current of the selected line as follows:

$I_{S}^{(k)}=I^{m}-\sum_{i=1}^{n_{u}} I_{L i}^{(k)}$

where $I^{m}$ is the during fault current measured at the head of the main feeder, $I_{L i}$ is the load current of the upstream network node $i, n_{u}$ is the total number of upstream nodes and $k$ denotes the iteration.

5) Having the selected line current $\left(I_{S}\right)$ and load currents $\left(I_{L i}\right)$, perform a backward sweep and calculate upstream network branch currents;

6) Having the branch currents and the during fault voltage measured at the head of the main feeder, perform a forward sweep and update the voltages of the upstream network nodes;

7) Repeat steps 3 to 6 until $I_{S}$ converges to a certain value, i.e.: 
$\max \left\{\left|I_{S}^{(k)}-I_{S}^{(k-1)}\right|\right\}<\varepsilon$

8) Report the calculated during fault voltage and current phasors of the selected line $\left(V_{S}\right.$ and $\left.I_{S}\right)$.

By assuming a pure resistive fault, and having $\left[V_{S}\right]=\left[V_{a}, V_{b}\right.$, $\left.V_{c}\right]^{\mathrm{T}}$ and $\left[I_{S}\right]=\left[I_{a}, I_{b}, I_{c}\right]^{\mathrm{T}}$, distance to fault from the line sending end $(d)$ can be calculated using the following equations [4]:

$$
d=\frac{\sum_{k=a, b, c}\left(V_{k}^{i} I_{f k}^{r}-V_{k}^{r} I_{f k}^{i}\right)}{\sum_{k=a, b, c} \sum_{j=a, b, c}\left(I_{f k}^{i}\left(I_{j}^{i} z_{k, j}^{i}-I_{j}^{r} z_{k, j}^{r}\right)+I_{f k}^{r}\left(I_{j}^{i} z_{k, j}^{r}+I_{j}^{r} z_{k, j}^{i}\right)\right)}
$$

where $r$ and $i$ are variables real and imaginary parts, $I_{f k}$ is the fault current of phase $k$, and $z k, j$ is the $j^{\text {th }}$ row, $i^{\text {th }}$ column element of the selected line impedance matrix.

The fault current can be calculated as follows:

$$
\left[I_{F}\right]=\left[I_{S}\right]-\left[I_{R}\right]
$$

where $\left[I_{R}\right]=\left[I_{r a}, I_{r b}, I_{r c}\right]^{\mathrm{T}}$ is the vector of fault downstream currents and $\left[I_{F}\right]=\left[I_{f a}, I_{f b}, I_{f c}\right]^{\mathrm{T}}$ is the vector of fault currents.

In equations (4) and (5), $V_{S}$ and $I_{S}$ are known values and $I_{R}$ and $d$ are the unknowns. The following iterative procedure is used to solve the equations and estimate the fault distance $(d)$ :

1) Assume the fault at the beginning of the line $(d=0)$;

2) Calculate voltage at the fault location:

$\left[V_{F}^{(k)}\right]=\left[V_{S}\right]-d^{(k)}[z]\left[I_{S}\right]$

where $k$ denotes the iteration.

3) Use $V_{F}$ to perform a load flow in the downstream network to calculate $I_{R}$;

4) Determine the fault current $\left(I_{F}\right)$ using (5);

5) Substitute $\left[I_{F}\right]$ into (4) to calculate $d$;

6) Repeat steps 2 to 5 until d converges to a certain value, i.e.:

$\left|d^{(k)}-d^{(k-1)}\right|<\varepsilon$

If the estimated fault distance for the selected line is less than the line length, it means that the fault is in that line. Thus, the proposed method reports the line number and the estimated distance. Otherwise, if the proposed method does not find the fault in any of the lines connected to the selected node, it selects the next node with the highest Index and repeats the process.

\section{CASE STUDY AND RESULTS}

The proposed method is evaluated by simulation studies on an overhead, real-life, $13.8 \mathrm{kV}, 134$-node distribution feeder [12]. The test system is simulated in the Alternative Transients Program (ATP).

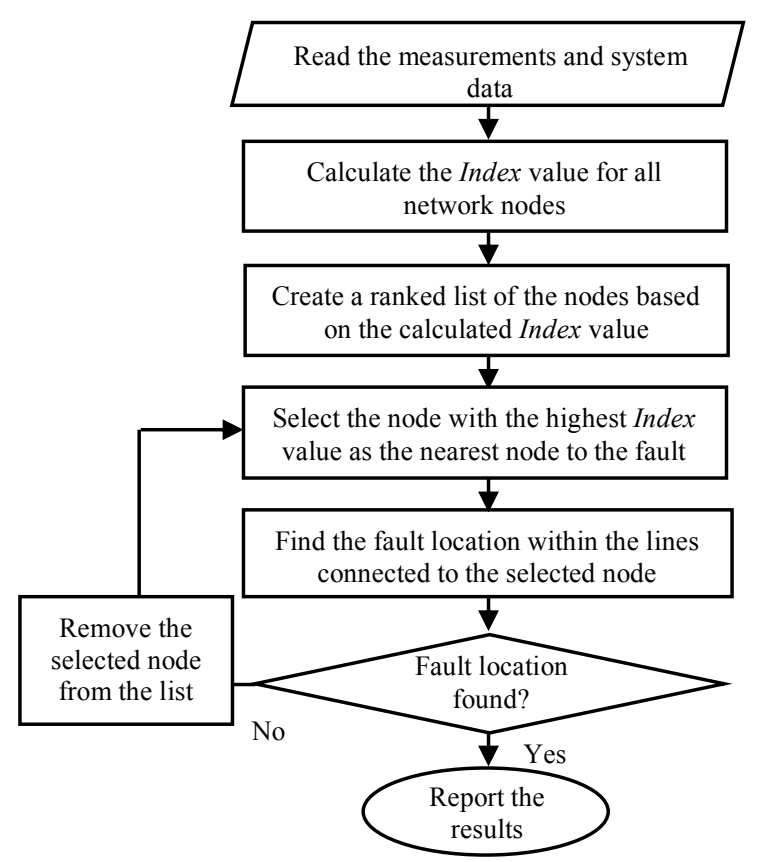

Fig. 2. Flowchart of the proposed fault location method

It is supposed that system data such as network topology, line impedances and load data are available. Five voltage measurements are arbitrarily placed in the system, at nodes 20 , $51,87,118$ and 127 to measure voltage sags.

In order to evaluate the effectiveness of the proposed fault location method, the results are compared with the impedancebased method proposed in [2] and the voltage sag-based method proposed in [9]. It should be noted that the voltage sagbased method identifies the nearest node to the actual location of the fault. Hence, the distance errors reported for this method are the distance between the actual fault location and the selected node. On the other hand, the impedance-based method estimates multiple locations for each fault scenario and the distance errors reported are for the best estimated fault location.

TABLE I shows the fault location errors in meter for different fault scenarios of single line to ground faults (AG). The results show that the proposed fault location method presents more accurate estimations. Compared to the impedance-based method, the voltage sag-based method has less accurate results. For example, for a single-phase to ground fault at line $74-75$ with $R_{f} 1 \Omega$, the voltage sag-based method selects node 74 which is $55 \mathrm{~m}$ away from the fault location, whilst the estimation errors of the proposed method and the impedance-based method are $0.04 \mathrm{~m}$ and $0.09 \mathrm{~m}$, respectively. For a three-phase fault at line 54-55, the voltage sag-based method selects node 58 as the nearest node to the fault location having an estimation error of $279 \mathrm{~m}$. This large error is a consequence of the fact that faults occurring around node 54 and node 58, will produce almost the same voltage sag magnitudes at the measurement nodes. For the same fault, the estimation errors of the proposed method and the impedancebased method are $0.07 \mathrm{~m}$ and $0.074 \mathrm{~m}$, respectively. Table II presents the results of the same tests performed for different fault types. 


\begin{tabular}{|c|c|c|c|c|c|c|c|c|c|c|c|c|}
\hline \multirow{3}{*}{ Methods } & \multicolumn{12}{|c|}{ Fault Cases } \\
\hline & \multicolumn{3}{|c|}{$\begin{array}{c}\text { Fault at line } 54-55 \\
39 \mathrm{~m} \text { from } 54\end{array}$} & \multicolumn{3}{|c|}{$\begin{array}{c}\text { Fault at line } 74-75 \\
55 \mathrm{~m} \text { from } 74 \\
\end{array}$} & \multicolumn{3}{|c|}{$\begin{array}{c}\text { Fault at line } 90-119 \\
44 \mathrm{~m} \text { from } 90 \\
\end{array}$} & \multicolumn{3}{|c|}{$\begin{array}{c}\text { Fault at line 109-110 } \\
15 \mathrm{~m} \text { from } 109\end{array}$} \\
\hline & $1 \Omega$ & $5 \Omega$ & $20 \Omega$ & $1 \Omega$ & $5 \Omega$ & $20 \Omega$ & $1 \Omega$ & $5 \Omega$ & $20 \Omega$ & $1 \Omega$ & $5 \Omega$ & $20 \Omega$ \\
\hline Proposed method & 0.02 & 0.26 & 1.02 & 0.04 & 0.09 & 0.14 & 0.07 & 0.24 & 1.25 & 0.019 & 0.24 & 1.02 \\
\hline Impedance-based method & 0.08 & 1.37 & 20.23 & 0.09 & 1.32 & 19.85 & 0.06 & 1.37 & 20.29 & 0.24 & 1.81 & 32 \\
\hline Voltage sag-based method & 279 & 279 & 229 & 55 & 55 & 55 & 44 & 44 & 44 & 15 & 15 & 15 \\
\hline
\end{tabular}

TABLE II. FAULT LOCATION ERROR IN METER FOR DIFFERENT FAULT TYPES

\begin{tabular}{|c|c|c|c|c|c|c|c|c|c|c|c|c|}
\hline \multirow{3}{*}{ Methods } & \multicolumn{12}{|c|}{$\begin{array}{l}\text { Fault Cases } \\
\end{array}$} \\
\hline & \multicolumn{3}{|c|}{$\begin{array}{c}\text { Fault at line } 54-55 \\
\text { 39m from } 54 \\
\end{array}$} & \multicolumn{3}{|c|}{$\begin{array}{l}\text { Fault at line } 74-75 \\
55 \mathrm{~m} \text { from } 74\end{array}$} & \multicolumn{3}{|c|}{$\begin{array}{c}\text { Fault at line } 90-119 \\
44 \mathrm{~m} \text { from } 90\end{array}$} & \multicolumn{3}{|c|}{$\begin{array}{c}\text { Fault at line 109-110 } \\
15 \mathrm{~m} \text { from } 109\end{array}$} \\
\hline & CA & BCG & ABCG & CA & BCG & ABCG & CA & BCG & ABCG & CA & BCG & ABCG \\
\hline Proposed method & 0.38 & 0.14 & 0.07 & 1.31 & 3.67 & 1.47 & 0.08 & 0.15 & 0.19 & 0.129 & 0.029 & 0.5 \\
\hline Impedance-based method & 0.38 & 0.49 & 0.074 & 2.15 & 3.96 & 0.92 & 0.67 & 0.47 & 0.19 & 0.297 & 0.253 & 0.61 \\
\hline Voltage sag-based method & 279 & 279 & 279 & 55 & 55 & 55 & 44 & 44 & 44 & 15 & 15 & 15 \\
\hline
\end{tabular}

TABLE III summarizes the minimum, mean and maximum estimation errors for all the studied scenarios. It can be seen that the proposed method is not only more accurate, but also less dependent on the fault resistance. The maximum error is just $3.67 \mathrm{~m}$, which is far lower than the other methods. The impedance-based method is the next accurate method with a maximum error of $32 \mathrm{~m}$.

The main advantage of the voltage sag-based method over the impedance-based method is the estimation of a single candidate for the fault location. As an example of the multiple estimation problem, Table IV lists 10 different fault location candidates reported by the impedance-based method and their distance to the actual fault location, for an AG fault at line 5455. The proposed method may also face the multiple estimation problem, but this rarely happens. Moreover, the estimated fault locations are always few and close to each other. For example, for a fault at line 90-119, in some cases, the proposed method reports both the faulted line and line $90-91$ as possible fault location.

\section{A. Results under non-ideal conditions}

In this section, the effect of load data uncertainties and measurement inaccuracies are studied to further evaluate the performance the proposed method. In order to test the influence of inaccurate load data on the proposed method, the data used for simulations is taken as the actual data and the erroneous load data is created by random variation of this data. Moreover, In order to evaluate the effect of measurement errors, random errors are added to magnitudes generated during simulations and the erroneous values are fed into the fault locator.

Four cases are considered to evaluate the performance of the method under non-ideal conditions:

Case 1) $20 \%$ random variation of all loads;

\section{TABLE III. THE MINIMUM, MAXIMUM AND MEAN ERRORS}

\begin{tabular}{|c|c|c|c|}
\hline Methods & $\begin{array}{c}\text { Minimum } \\
\text { error }\end{array}$ & $\begin{array}{c}\text { Mean } \\
\text { error }\end{array}$ & $\begin{array}{c}\text { Maximum } \\
\text { error }\end{array}$ \\
\hline Proposed method & 0.019 & 0.47 & 3.67 \\
\hline $\begin{array}{c}\text { Impedance-based } \\
\text { method }\end{array}$ & 0.06 & 4.55 & 32 \\
\hline $\begin{array}{c}\text { Voltage sag-based } \\
\text { method }\end{array}$ & 15 & 96.17 & 279 \\
\hline
\end{tabular}

TABLE IV. MULTIPLE FAULT LOCATIONS REPORTED BY THE IMPEDANCEBASED METHOD AND THEIR ERROR, FOR AN AG FAULT AT LINE 54-55

\begin{tabular}{|c|c|}
\hline Reported line and distance & Distance to actual fault location (m) \\
\hline Line $78-89$ at $5.68 \mathrm{~m}$ from 78 & 434.65 \\
\hline Line $78-79$ at $23.23 \mathrm{~m}$ from 78 & 452.23 \\
\hline Line $67-71$ at $14.88 \mathrm{~m}$ from 68 & 443.87 \\
\hline Line $67-69$ at $14.97 \mathrm{~m}$ from 67 & 443.97 \\
\hline Line $57-59$ at $23.91 \mathrm{~m}$ from 57 & 252.91 \\
\hline Line $78-88$ at $14.23 \mathrm{~m}$ from 78 & 443.24 \\
\hline Line $67-68$ at $14.92 \mathrm{~m}$ from 67 & 443.92 \\
\hline Line $57-58$ at $23.94 \mathrm{~m}$ from 57 & 252.94 \\
\hline Line $50-51$ at $159.6 \mathrm{~m}$ from 50 & 419.59 \\
\hline Line $54-55$ at $33.76 \mathrm{~m}$ from 54 & 5.23 \\
\hline
\end{tabular}

Case 2) $1 \%$ random variation of all measurements;

Case 3 ) 50\% random variation of all loads;

Case 4) $50 \%$ random variation of all loads and $1 \%$ random variation of all measurements. 
The results are summarized in Table V. Comparing Case 1 and Case 3 and ideal condition reveals that the load data errors affect the accuracy of the impedance-based method though its results are always satisfactory. On the other hand, the voltage sag-based method is affected by either load data or measurement errors. For example, for a fault at line 74-75, the variation of all measurements within $1 \%$ of deviation has led to large estimation errors. Whilst the impedance-based method produces more accurate results, the major advantage of the voltage sag-based method over the impedance-based method is the estimation of a single candidate for the fault location. The proposed method in this paper merges the good features of both methods. After identification of the nearest node to fault location, it investigates the lines connected to the selected node and ensures its correctness. It also identifies the accurate fault location improving the overall accuracy. In this manner, the proposed method not only produces more accurate results in almost all cases, but also overcomes the multiple estimation problem and improves results dependability.

\section{CONCLUSION}

This paper presents a new fault location method that satisfies the required features of accuracy and reliability for advanced outage management systems. The proposed method is tested by simulation studies for different fault types, positions, and resistances. The method is compared with two of the most prominent voltage-sag-based [9] and impedancebased [2] methods. The proposed method in this paper merges the good features of both methods. It investigates the lines connected to the selected node to ensure its correctness and also identifies the accurate fault location improving the overall accuracy.

The simulation results verify the superior accuracy and reliability of the proposed method even when there are measurement and load data errors, showing its potential for practical applications. Accuracy test results show that the proposed method has a mean estimation error of 0.47 meters which is far lower than the other methods. Moreover, it does not face the multiple estimation problem as the impedancebased methods do. The performance of the proposed method is also studied for the effect of load data errors and measurement inaccuracies. Since the proposed method does not use sparse voltage measurements for accurate fault location, its results are not much affected by measurements inaccuracies. Moreover, the proposed method is less affected by load data errors, when compared to the impedance-based method. With a random variation of all loads and measurements within $50 \%$ and $1 \%$ of deviations respectively, the maximum error of the proposed method has been less than 4 meters.

\section{REFERENCES}

[1] A. Bahmanyar, S. Jamali, A. Estebsari, and E. Bompard, "A comparison framework for distribution system outage and fault location methods," Electr Pow Syst Res, vol. 145, pp. 19-34, 2017.

[2] R. Salim, M. Resener, A. Filomena, K. De Oliveira and A. Bretas, "Extended fault-location formulation for power distribution systems," IEEE Trans. Power Del., vol. 24, pp. 508-516, 2009.

[3] C. Orozco-Henao, A. Bretas, R. Chouhy-Leborgne, A. Herrera-Orozco, and J. Marín-Quintero, "Active distribution network fault location methodology: A minimum fault reactance and Fibonacci search approach," Int J Electric Power Energy Sys, vol. 84, pp. 232-241, 2017.

[4] A. Bahmanyar, S. Jamali, " Fault location in active distribution networks using non-synchronized measurements," Int J Electric Power Energy Sys, vol. 91, pp. 451-458, 2017.

[5] H. Hizman, P. Crossley, P. Gale, and G. Bryson, "Fault section identification and location on a distribution feeder using travelling waves," in Power Engineering Society Summer Meeting, 2002, pp. 1107-1112.

[6] M. Goudarzi, B. Vahidi, R. Naghizadeh, and S. Hosseinian, "Improved fault location algorithm for radial distribution systems with discrete and continuous wavelet analysis," Int J Electr Power Energy Syst, vol. 67, pp. 423-430, 2015.

[7] D. Thukaram, H. Khincha, and H. Vijaynarasimha, "Artificial neural network and support vector machine approach for locating faults in radial distribution systems," IEEE Trans. Power Del., vol. 20, pp. 710721, 2005.

[8] A. Rafinia and J. Moshtagh, "A new approach to fault location in threephase underground distribution system using combination of wavelet analysis with ANN and FLS," Int J Electric Power Energy Sys, vol. 55, pp. 261-274, 2014.

[9] R.. Pereira, L. Silva, M. Kezunovic, and J. Mantovani, "Improved fault location on distribution feeders based on matching during-fault voltage sags," IEEE Trans. Power Del., vol. 24, pp. 852-862, 2009.

[10] Y. Dong, C. Zheng, M. Kezunovic, Enhancing accuracy while reducing computation complexity for voltage-sag-based distribution fault location, IEEE Trans. Power Del., 28 (2013) 1202-1212.

[11] S. Jamali, A. Bahmanyar, E. Bompard " Fault location method for distribution networks using smart meters," Measurement, vol. 102, pp. 150-157, 2017.

[12] F. Trindade, W. Freitas, J. Vieira, Fault location in distribution systems based on smart feeder meters, IEEE Trans. Power Del., 29 (2014) 251260.

[13] A. Bahmanyar, A. Estebsari, A. Bahmanyar, E. Bompard "Nonsy load flow: Smart grid load flow using non-synchronized measurements," Measurement, in IEEE international conference on environment and electrical engineering, Milan, 2017.

TABLE V. DISTANCE BETWEEN THE ESTIMATED AND ACTUAL FAULT POINTS IN METER UNDER NON-IDEAL CONDITIONS

\begin{tabular}{|c|c|c|c|c|c|c|c|c|c|c|c|c|}
\hline \multirow{2}{*}{ Cases under study } & \multicolumn{3}{|c|}{$\begin{array}{c}\text { Fault at line } 54-55 \\
39 \mathrm{~m} \text { from } 54\end{array}$} & \multicolumn{3}{|c|}{$\begin{array}{c}\text { Fault at line } 74-75 \\
55 \mathrm{~m} \text { from } 74\end{array}$} & \multicolumn{3}{|c|}{$\begin{array}{c}\text { Fault at line } 90-119 \\
44 \mathrm{~m} \text { from } 90\end{array}$} & \multicolumn{3}{|c|}{$\begin{array}{c}\text { Fault at line } 109-110 \\
15 \mathrm{~m} \text { from } 109\end{array}$} \\
\hline & PM & VBM & IBM & PM & VBM & IBM & PM & VBM & IBM & PM & VBM & IBM \\
\hline Case 1 & 0.56 & 229 & 5.24 & 0.17 & 55 & 5.09 & 0.64 & 44 & 5.27 & 0.52 & 15 & 7.91 \\
\hline Case 2 & 0.95 & 269 & 7.13 & 1.11 & 325 & 6.87 & 1.14 & 66 & 7.44 & 1.22 & 15 & 10.01 \\
\hline Case 3 & 1.56 & 229 & 10.21 & 2.46 & 55 & 9.43 & 2.59 & 44 & 10.11 & 3.43 & 15 & 10.96 \\
\hline Case 4 & 1.87 & 229 & 24.66 & 2.75 & 55 & 19.43 & 3.92 & 44 & 26.83 & 3.65 & 245 & 20.44 \\
\hline
\end{tabular}

PM: Proposed method, IBM: Impedance-based method, VBM: Voltage sag-based method 